accordance with the requirements of today. That is, organization of the educational process, which aims at shaping the willingness of future teachers of physical education to study in local lore, is to create conditions for students to form the experience of a particular activity, different ways of practical activity, as well as the value attitude to the surrounding reality.

On the basis of the analysis of scientific sources, pedagogical conditions of preparation of future physical culture teachers for local lore activity are substantiated, namely: stimulation of positive motivation of future physical education teachers for assimilation of the content of educational material on organization of local lore; improvement of the content of the educational material of the disciplines of the cycle of general (fundamental) and professional (scientific-subject) training on the issues of organization of local lore; identifying forms, methods and teaching aids that facilitate organization of local lore on the basis of a competence approach; acquisition of experience of local lore by future teachers of physical culture during educational and pedagogical practices.

Key words professional teacher training, educational process, local lore, physical culture, competence, pedagogical technologies.

удк 378.6.656

Олена Саркісова

Льотна академія

Національного авіаційного університету

ORCID ID 0000-0002-3022-1395

DOI 10.24139/2312-5993/2019.07/285-293

\title{
СТРУКТУРНІ КОМПОНЕНТИ МОДЕЛІ ФОРМУВАННЯ ПРОФЕСІЙНОГО СТАНОВЛЕННЯ МАЙБУТНІХ МЕНЕДЖЕРІВ АВІАЦІЙНОЇ ГАЛУЗІ У ПРОЦЕСІ ФАХОВОЇ ПІДГОТОВКИ
}

У статті розкривається модель формування професійного становлення менеджерів авіаційної галузі у процесі фахової підготовки. На основі методу наукового моделювання визначено основні структурні елементи моделі, схарактеризовано їх сутність та взаємозв'язки. Модель складається з чотирьох взаємопов'язаних етапів, а саме: організаційного, змістового, процесуального та оцінно-результативного. Аналізується зміст кожного етапу. На основі розроблених компонентів, критеріїв і показників виокремлено три рівні професійного становлення: високий (професійний), середній (достатній) та низький (базовий), що потребує корегування процесу формування професійного становлення.

Ключові слова: етапи професійного становлення, менеджер авіаційної галузі, модель, моделювання, професійне становлення.

Постановка проблеми. Професійне становлення фахівців, зокрема менеджерів авіаційної галузі, набуває особливого значення в умовах мінливої дійсності, особливо під час соціально-економічних перетворень, що наразі відбуваються в суспільстві. Вища освіта в умовах сьогодення повинна створювати необхідні умови для підготовки майбутнього конкурентоспроможного фахівця, який буде відповідати сучасним вимогам ринку праці. Зокрема, менеджер авіаційної галузі $\epsilon$ однією з ключових професій у світі авіації, який $є$ професійним керівником, здійснює 
планування, організацію, координацію, мотивацію та контроль діяльності авіаційних підприємств на ринках авіаційних послуг.

У зв'язку з цим актуальним $€$ вдосконалення процесу навчання майбутніх менеджерів авіаційної галузі. Покращити результат цієї підготовки можна за умови впровадження в освітній процес науково обґрунтованої моделі формування професійного становлення менеджерів авіаційної галузі у процесі фахової підготовки.

Аналіз останніх досліджень. Теоретичне обґрунтування професійного становлення здійснили В. Бодров, Н. Волянюк, Е. Зеєр, М. Козирєва та Ю. Козловська, В.Лисовський, В. Орлова, М. Осіпов, Ю. Поваренков, В. Слободчиков та інші, загальні положення створення моделі формування професійного становлення базоване на працях багатьох науковців, а саме: С. Вітвицької, К. Гнезділової, А. Дахіна, Г. Клауса, Є. Лодатко, А. Остапенко, В. Пікельна, В.Штоффа, В.Ягупова та інших. Створення структурних компонентів моделі основане на працях О.Бродової, Г.Герасименко, О. Остапенко, Г. Пухальської та інших. Однак, попри наявність значної кількості наукових досліджень з означеного питання, поза увагою науковців залишилось питання розгляду структурних компонентів моделі формування професійного становлення саме майбутніх менеджерів авіаційної галузі.

Метою статті $€$ структурні компоненти моделі, яка відтворює загальну систему формування професійного становлення менеджерів авіаційної галузі у процесі фахової підготовки.

Методи дослідження. Для досягнення поставленої мети в статті використано такі методи дослідження, як: аналіз наукової літератури з проблеми формування професійного становлення менеджерів авіаційної галузі у процесі фахової підготовки та узагальнення отриманих даних; метод наукового моделювання для визначення основних структурних елементів моделі.

Виклад основного матеріалу дослідження. Більшість авторів виокремлює певні блоки в побудові запропонованих ними моделей. Так, О. Остапенко (Остапенко, 2014) у своєму дослідженні в процесі моделювання виділила п'ять блоків формування професійної культури менеджерів: 1) концептуальна основа; 2) процесуальна частина; 3) програмно-методичне забезпечення; 4) діагностичний інструментарій; 5) кінцевий результат. На думку Г. Герасименко, структурно-функціональна модель має складатися $з$ чотирьох взаємопов'язаних блоків, а саме: організаційного, змістового, технологічного та оцінно-результативного (Герасименко, 2015). О Бродова (Бродова, 2014) запропонувала дидактичну модель, що містить всі компоненти методики та складається з цільової, теоретичної, операційної та контрольно-діагностичної складових. Створюючи модель системи формування комунікативної компетентності майбутніх пілотів цивільної авіації, Г. Пухальська (Пухальська, 2011) використала чотири блоки: блок управління, блок умов, процесуальний блок та результативний. 
У результаті аналізу науково-педагогічної літератури було з'ясовано, що процес моделювання має складатися на основі єдності мети, завдань, принципів, педагогічних умов, критеріїв функціонування як системи в цілому, так і окремих ії підсистем. Всі елементи моделі $\epsilon$ взаємопов'язаними та мають власне місце в загальній структурі, яка координується цілеспрямованістю моделі. На нашу думку, модель формування професійного становлення менеджерів авіаційної галузі має складатися з чотирьох взаємопов'язаних етапів, а саме: організаційного, змістового, процесуального та оцінно-результативного (рис. 1).

Перший, організаційний, етап включає в себе мету, завдання та принципи професійного становлення менеджерів авіаційної галузі. Мета полягає у формуванні професійного становлення майбутніх менеджерів авіаційної галузі у процесі фахової підготовки.

Мета процесу професійного становлення менеджерів авіаційної галузі досягається вирішенням низки завдань:

- розвитком стійкої мотивації до майбутньої професійної діяльності в авіаційній галузі;

- формуванням системи теоретичних знань із професійноорієнтованих дисциплін, що $\epsilon$ основою когнітивного компонента професійного становлення менеджерів авіаційної галузі;

- прагненням до самовдосконалення, саморозвитку та самоосвіти;

- розвитком системи вмінь та навичок, вироблених у процесі проходження практики, які слугують підґрунтям праксеологічного компонента професійного становлення менеджерів авіаційної галузі.

Так, для вирішення вищезгаданих завдань необхідно, щоб процес навчання здійснювався на базі певних принципів навчання. Ми погоджуємося з думкою М. Фіцули (Фіцула, 2006) щодо принципів педагогічної моделі, що в навчальному процесі вищої школи дотримуються загально-дидактичних і специфічних принципів навчання, які ми і виокремимо.

Відповідно до тематики нашого дослідження із загальнодидактичних принципів навчання ми виділімо наступні:

1. Принцип системності й послідовності. Він зорієнтований на системне і послідовне викладання і вивчення навчального матеріалу. Йдеться про фіксування уваги студента на вузлових питаннях, логічний перехід від засвоєного матеріалу до нового тощо. Залежно від змісту роботи, їі цілей викладач застосовує певну систему методів навчання, ведучи студентів від простого відтворення до самостійних творчих дій із вивченим матеріалом. Навчальний матеріал має бути вибудуваний на системі взаємозв'язків елементів світу, який оточує студента (Фіцула, 2006). У контексті нашого дослідження принцип системності й послідовності передбачає послідовне та логічне здобуття знань із фахових дисциплін, забезпечення внутрішньо-предметних та міжпредметних змістових і методичних зв'язків фахових дисциплін. 


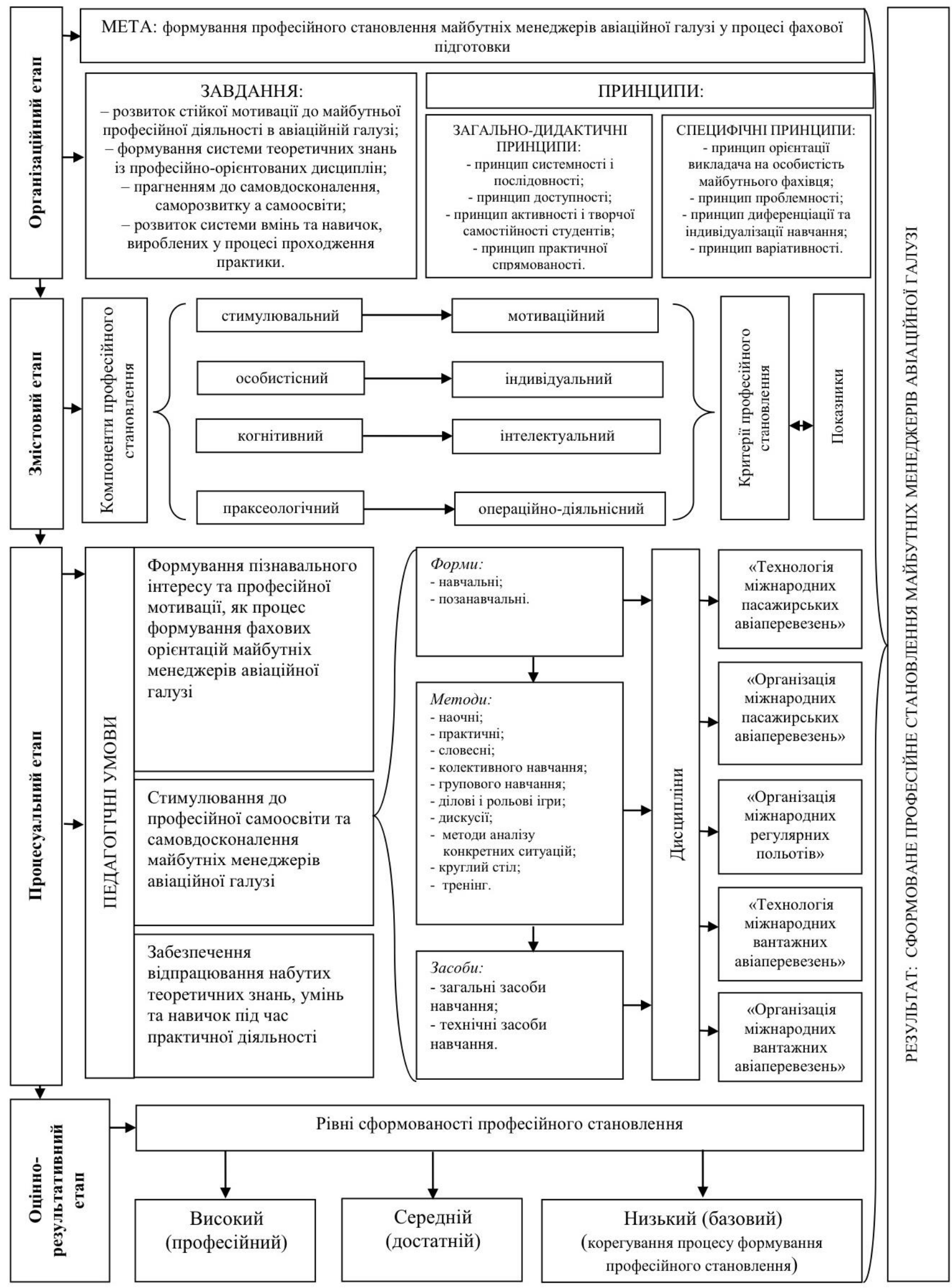

Рис. 1. Модель формування професійного становлення менеджерів авіаційної галузі у процесі фахової підготовки 
2. Принцип доступності. Успішність та ефективність навчання визначаються відповідністю його змісту, форм і методів віковим особливостям студентів, їх можливостям. Реалізація цього принципу передбачає дотримання правил: від простого - до складного, від відомого до невідомого, від близького - до далекого, а також урахування рівня розвитку студентів, їх індивідуальних особливостей. Він вимагає також визначення норм витрат часу і праці, рівня напруження і культури розумової та фізичної праці студентів. У навчальному процесі недопустимі як перенавантаження, так і недовантаження студентів, що передбачено освітніми стандартами і рівнями навчання, тобто йдеться про диференціацію навчально-виховного процесу (Фіцула, 2006). У контексті нашої тематики принцип доступності передбачає формування змісту фахових дисциплін із вибором основного змістовного професійно-спрямованого матеріалу; забезпечення відповідності обсягу позааудиторних завдань установленим нормам розподілу годин навчального навантаження; використання достатньої кількості фактів, прикладів при викладенні професійноорієнтованих дисциплін; розподіл навчального навантаження на студентів із урахуванням їх можливостей та спроможностей.

3. Принцип активності і творчої самостійності студентів та їх відповідальності за результати навчально-пізнавальної діяльності. Цей принцип передбачає опору на активність студентів при спрямовуючій та стимулюючій ролі викладача: той, хто навчається, повинен бути суб'єктом творчої пізнавальної діяльності, який чітко усвідомлює мету навчання, вміє планувати і організовувати свою роботу, здійснювати ії самоаналіз і самоконтроль, усвідомлювати відповідальність за результати навчально-пізнавальної діяльності. Логічною вимогою до конструювання навчального процесу у вищій школі має бути гармонійне поєднання науково-дослідної i навчально-пізнавальної діяльності студентів, що передбачає створення й функціонування такої організації навчального процесу, яка спроможна забезпечити формування (за умови сприйняття і засвоєння системи сучасного наукового знання) спеціаліста, здатного до творчої праці в певній галузі народного господарства. У зв'язку з цим необхідно залучати студентів до участі в наукових гуртках, олімпіадах, творчих конкурсах, проведенні наукових досліджень, стимулювати їх творчі здібності (Гладуш, 2014). Тому вбачаємо за необхідне задля реалізації даного принципу введення в процес навчання тренінгів, частково-пошукових бесід, ділових ігор, дискусій, круглих столів тощо.

4. Принцип практичної спрямованості.

Основними напрямами реалізації принципу постають:

- розкриття значення теоретичних знань у практичній діяльності та загалом у життєдіяльності людини;

- введення в навчальні курси професійно значущого матеріалу й формування професійно значущих умінь; 
- організація практичної діяльності (участь у семінарах, виконання лабораторних робіт, проходження виробничої практики, підготовка наукових робіт) із метою набуття вмінь застосовувати отримані у ЗВО знання на практиці (Гладуш, 2014). Реалізація даного принципу передбачає практикоорієнтований характер навчання, зв'язок із існуючим досвідом менеджерів авіаційної галузі, раціональне застосування дуальної освіти, що забезпечує паралельне засвоєння теоретичних знань і формування практичних умінь.

Для більш ефективного формування професійного становлення необхідно застосувати ще й специфічні принципи. Дані принципи відображають сутність та особливий характер зв'язків всередині системи і дають конкретно-дидактичні орієнтири побудови процесу навчання.

Виділимо такі специфічні принципи:

1. Принцип орієнтації викладача на особистість майбутнього фахівця характеризує професіоналізм викладача, який здатен до активної навчальної діяльності, розвитку мотиваційної сфери студента, 3 урахуванням вікових та індивідуальних особливостей кожного студента.

2. Принцип проблемності. У вищій школі проблемне навчання може застосовуватися на різних етапах процесу навчання - на етапі здобування студентами нових знань (проблемні лекції), на етапі закріплення (дослідницька i, частково, пошукова діяльність студентів на семінарських, практичних, лабораторних заняттях), у процесі виконання курсових i дипломних робіт.

3. Принцип диференціації та індивідуалізації навчання являє собою врахування індивідуальних особливостей кожного студента, поєднання групових та індивідуальних занять, активних та інтерактивних форм організації навчального процесу.

Даний принцип вимагає:

- ураховувати рівень знань, умінь і навичок кожного студента;

- здійснювати аналіз досвіду студентів;

- надавати індивідуальну допомогу студентам під час будь-яких навчальних завдань.

4. Принцип варіативності - наявність та можливість вибору певного варіанту у процесі виконання завдань залежно від особливостей практичної діяльності.

У зв'язку з тим, що виокремленні на основі аналізу професійнокваліфікаційних вимог до менеджера авіаційної галузі та психологопедагогічної літератури компоненти (стимулювальний, особистісний, когнітивний та праксеологічний) та критерії (мотиваційний, індивідуальний, інтелектуальний та операційно-діяльнісний) професійного становлення формуються у процесі професійної підготовки, то вони становлять змістовий етап моделі. 
Процесуальний етап моделі включає форми, методи, засоби та навчальні дисципліни, вибір яких залежить від педагогічних умов формування професійного становлення менеджерів авіаційної галузі. Цей етап спрямований: на засвоєння майбутніми фахівцями авіаційного менеджменту теоретичних, прикладних умінь і навичок; підготовку до професійної діяльності.

Реалізація процесу професійного становлення майбутніх менеджерів авіаційної галузі здійснюється за допомогою таких методів, як: наочні, практичні, словесні; та активних методів: методи колективного, групового навчання, ділові і рольові ігри, дискусії, методи аналізу конкретних ситуацій, круглий стіл, тренінг тощо. Всі ці методи створюють єдину систему, цілісність якої забезпечує ефективність професіональної підготовки. Методика ґрунтується на збагаченні програмно-методичного забезпечення кожної професійно орієнтованої дисципліни варіативного компоненту професійною спрямованістю, яка дозволяє розкрити на лекційних заняттях теоретичний зміст майбутньої спеціальності, ії складові, функції, а також проведення практичних і семінарських занять, організовану самостійну роботу студентів, 3 використанням зазначених методів навчання.

Відповідно до запропонованих форм та обраних методів навчання майбутніх менеджерів авіаційної галузі ми обрали засоби навчання задля професійного становлення. На наш погляд, ефективна підготовка майбутніх фахівців можлива за умов використання загальних засобів навчання, а саме: навчальних методичних посібників, інтерактивних комплексів дисциплін, таблиць, тестів тощо та технічних засобів навчання: мультимедійних презентацій із використанням кінопроектора, телевізора, посібники динамічної проекції (кінофільми, кінофрагменти) тощо.

Програмно-методичне забезпечення формування професійного становлення менеджерів авіаційної галузі є інтеграцією змісту навчального матеріалу різних навчальних дисциплін, а саме: «Технологія міжнародних пасажирських авіаперевезень», «Організація міжнародних пасажирських авіаперевезень», «Організація міжнародних регулярних польотів», «Технологія міжнародних вантажних авіаперевезень» та «Організація міжнародних вантажних авіаперевезень», а також інтеграцією різних видів виховної діяльності.

Під час вивчення кожної дисципліни та після закінчення здійснюється контроль за результатами діяльності майбутніх менеджерів авіаційної галузі, що заснований на рейтинговій оцінці. Рейтингова оцінка враховує перевірку рівня знань та вмінь за допомогою усної дискусії, уміння вирішувати тестові завдання, перевірку самостійної роботи студента; крім того, уміння вести конспект лекцій, виконувати індивідуальні завдання, презентувавши їх виступати 3 доповідями, вирішувати типові та творчі/ситуаційні завдання тощо. 
Під час оцінно-результативного етапу ми урахували аспекти виокремлення рівнів сформованості основних компонентів і критеріїв професійного становлення, які представлено діагностичним інструментарієм моделі. На основі розроблених компонентів, критеріїв і показників було виокремлено три рівні професійного становлення: високий (професійний), середній (достатній) та низький (базовий), що потребує коригування процесу формування професійного становлення.

Таким чином, розроблена модель формування професійного становлення, а також алгоритм управління цим процесом дає можливість зрозуміти явище формування професійного становлення менеджерів авіаційної галузі у структурі професійної підготовки в його цілісності та 3 урахуванням окремих елементів; аналізувати недоліки та переваги цього процесу. Завдяки практичній реалізації створеної моделі отримаємо сформоване професійне становлення майбутніх менеджерів авіаційної галузі у процесі фахової підготовки.

Висновки та перспективи подальших наукових розвідок. Наведена модель формування професійного становлення майбутніх менеджерів авіаційної галузі була розроблена на основі компонентного аналізу, згідно з яким до неї входять організаційний, змістовий, процесуальний та оціннорезультативний етапи. Надана загальна характеристика цих етапів, що дало змогу виділити призначення кожного з них. Представлену модель професійного становлення майбутнього менеджера авіаційної галузі ми розглядаємо як систему, яка є частиною структури більш високого порядку підготовки фахівців з авіаційного менеджменту професійної діяльності. Перспективу подальших досліджень ми вбачаємо в реалізації запропонованої моделі в навчальній діяльності.

\section{ЛІТЕРАТУРА}

Бродова, О. В. (2014). Педагогічні умови формування комунікативних умінь майбутніх пілотів у процесі вивчення психолого-педагогічних дисциплін (автореф. дис. ... канд. пед. наук: 13.00.04). Київ (Brodova, O. V. (2014). Pedagogical conditions for the formation of communicative skills of future pilots in the process of studying psychological and pedagogical disciplines (DSc thesis abstract). Kyiv).

Герасименко, Г.В.(2015). Формування фахових компетентностей курсантів льотних навчальних закладів у прочесі вивчення фундаментальних дисциплін (автореф. дис. ... канд. пед. наук). Запоріжжя (Herasymenko, H. V. (2015). Formation of professional competences of cadets of flying schools in the process of studying fundamental disciplines (DSc thesis abstract). Zaporizhzhia).

Гладуш, В. А., Лисенко, Г. І. (2014). Педагогіка вищої школи: теорія, практика, історія. Дніпропетровськ (Hladush, V. A., Lysenko, H. I. (2014). Higher education pedagogy: theory, practice, history. Dnipropetrovsk).

Остапенко, О.М.(2014). Формування професійної культури менеджерів зовнішньоекономічної діяльності у фаховій підготовці (дис. ... канд. пед. наук: 13.00.04). Кіровоград (Ostapenko, О. М. (2014). Formation of professional culture of foreign economic activity managers in professional training (PhD thesis). Kirovohrad). 
Пухальська, Г. А. (2011). Педагогічні умови фрормування комунікативної компетентності у майбутніх пілотів цивільної авіації (дис. ... канд. пед. наук: 13.00.04). Черкаси (Pukhalska, Н. A. (2011). Pedagogical conditions for the formation of communicative competence in future civil aviation pilots (PhD thesis). Cherkasy).

Фіцула, М. М. (2006). Педагогіка вищої школи. К.: «Академвидав» (Fitsula, М. М. (2006). Pedagogy of higher school. K.: "Academvydav").

\section{PEЗЮME}

Саркисова Елена. Структурные компоненты модели формирования профессионального становления будущих менеджеров авиационной отрасли в процессе профессиональной подготовки.

В статье раскрывается модель формирования профессионального становления менеджеров авиационной отрасли в процессе профессиональной подготовки. На основе метода научного моделирования определены основные структурные элементы модели, охарактеризованы их сущность и взаимосвязи. Модель состоит из четырех взаимосвязанных этапов, а именно: организационного, содержательного, процессуального и оценочно-результативного. Анализируется содержание каждого этапа. На основе разработанных компонентов, критериев и показателей были выделены три уровня профессионального становления: высокий (профрессиональный), средний (достаточный) и низкий (базовый), что требует корректировки процесса формирования профессионального становления.

Ключевые слова: этапы профессионального становления, менеджер авиационной отрасли, модель, моделирование, профессиональное становление.

\section{SUMMARY}

Sarkisova Olena Structural components of the model of professional development formation of future aviation industry managers in professional preparation process.

The article reveals the model of professional development formation of aviation industry managers in the process of professional training. Based on the method of scientific modeling, the main structural elements of the model are determined, their essence and interconnections are characterized. The model consists of four interrelated stages, namely: organizational, content, procedural and evaluative-productive. The content of each stage is analyzed. Thus, the first, organizational, stage includes the purpose, tasks and principles of the professional development of aviation industry managers. The content of the model consists of components (stimulating, personal, cognitive and praxeological) and criteria (motivational, individual, intellectual, and operational-activity) of professional formation, which are formed in the process of professional training. The procedural stage includes forms, methods, means and disciplines, the choice of which depends on the pedagogical conditions for the formation of professional development of aviation industry managers. This stage is aimed at: mastering the theoretical, applied skills and skills of future specialists in aviation management; preparation for professional activity. The estimated and productive stage considers the aspects of distinguishing the levels of formation of the main components and criteria for professional development. Based on the outlined components, criteria and indicators, three levels of professional development are identified: high (professional), average (sufficient) and low (basic), which requires adjusting the process of professional development formation.

Key words stages of professional formation, aviation industry manager, model, modeling, professional formation. 